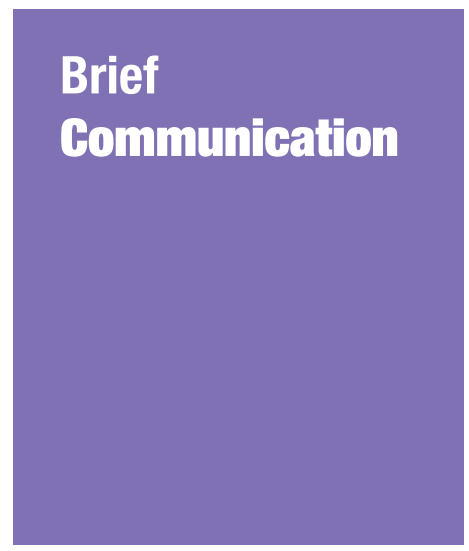

Submitted: 29 Dec 2016 Accepted: 23 Feb 2017 Online: 14 Apr 2017

\section{Deep Brain Stimulation (DBS) for Movement Disorders: An Experience in Hospital Universiti Sains Malaysia (HUSM) Involving 12 Patients}

\author{
LıM Liang Hooi ${ }^{1}$, Diana Noma Fitzrol ${ }^{1,2}$, Senthil Kumar \\ Rajapathy ${ }^{1}, T_{\text {an }}$ Yew Chin ${ }^{1,2}$, SanihaH Abdul Halim ${ }^{1}$, Regunath \\ KANDASAMY ${ }^{1,2}$, Wan Mohd Nazaruddin Wan HaSSAN ${ }^{3}$, BaDRISYAH \\ Idris ${ }^{1,2}$, ABdul Rahman IzaINI Ghani ${ }^{1,2}$, ZAMZURI Idris ${ }^{1,2}$, John \\ Tharakan ${ }^{1,2}$, Sarun Nunta-AreE ${ }^{4}$, Jafri Malin Abdullah ${ }^{1,2}$
}

1 Department of Neurosciences, School of Medical Sciences, Universiti Sains Malaysia, 16150 Kubang Kerian, Kelantan, Malaysia

2 Center for Neuroscience Services and Research, Universiti Sains Malaysia, 16150 Kubang Kerian, Kelantan, Malaysia

3 Department of Anaesthesiology, School of Medical Sciences, Universiti Sains Malaysia, 16150 Kubang Kerian, Kelantan, Malaysia

4 Faculty of Medicine Siriraj Hospital, Mahidol University, Jainadnarendhranusorn Bld. (Bld. No. 59), 3rd Floor, Room No. 323, 2 Wanglang Road Bangkoknoi, Bangkok 1070o, Thailand

To cite this article: Lim LH, Diana NF, Rajapathy SK, Tan YC, Sanihah AH, Kandasamy R, Wan Hassan WMN, Badrisyah I, Abdul Rahman Izaini G, Zamzuri I, Tharakan J, Nunta-Aree S, Jafri Malin A. Deep brain stimulation (DBS) for movement disorders: an experience in Hospital Universiti Sains Malaysia (HUSM) involving 12 patients. Malays J Med Sci. 2017;24(2):87-93. https://doi.org/10.21315/mjms2017.24.2.11

To link to this article: https://doi.org/10.21315/mjms2017.24.2.11

\begin{abstract}
Deep brain stimulation (DBS) was first introduced in 1987 to the developed world. As a developing country Malaysia begun its movement disorder program by doing ablation therapy using the Radionics system. Hospital Universiti Sains Malaysia a rural based teaching hospital had to take into consideration both health economics and outcomes in the area that it was providing neurosurgical care for when it initiated its Deep Brain Stimulation program. Most of the patients were from the low to medium social economic groups and could not afford payment for a DBS implant. We concentrated our DBS services to Parkinson's disease, Tourette's Syndrome and dystonia patients who had exhausted medical therapy. The case series of these patients and their follow-up are presented in this brief communication.
\end{abstract}

Keywords: deep brain stimulation, Malaysia, movement disorders, dystonia, Parkinson

\section{Introduction}

Electrical stimulation of the central nervous system has been long utilised by humankind since the Roman and Greek civilisations (1). In $43 \mathrm{AD}$, Scribonious Largus detailed in his book, 'Compositiones Medicamentorum', how the Romans used to treat headaches and gout with electric torpedo fish $(2,3)$. However, it was not until much later in the 18th century that Galvani established through his experiments that the brain generates electrical impulses which spread down through the nerves and to the muscles (4). Throughout the 19th century, scientists have experimented with electrical brain stimulation in animals, and, in 1874, Bartholow was the first to conduct and report findings of cerebral cortex stimulation in an awake patient (5). 
The first example of therapeutic brain stimulation in the 2oth century was demonstrated by Cerletti in 1938 for severe psychosis (6). Later on, studies emerged on the use of brain stimulation for pain control and other psychiatric diseases (5). These led to the development of functional neurosurgery, including deep brain stimulation (DBS) (5). In 1962, Jose Delgado, a Spanish neuroscientist, described the technique of implanting intracranial electrodes and their role in diagnosing and possibly managing patients with mental disorders (7).

Up until the present day, DBS has been more widely used for neurological and psychiatric conditions, such as movement disorders (Idiopathic Parkinson's Disease, dystonia, Tourette's syndrome), chronic pain syndrome, obsessive compulsive disorder and refractory epilepsy. In this article, we describe our experience managing 12 patients who underwent DBS at Hospital Universiti Sains Malaysia.

\section{Hospital setting}

Hospital Universiti Sains Malaysia (HUSM) is a government funded, tertiary medical institution founded in 1979. Located in the state of Kelantan, it serves the East Coast community in Malaysia. HUSM currently has its own Department of Neurosciences consisting of Neurology, Neurosurgery, Neuroanesthesiology and Critical Care, Neurorehabilitation and Neurophysiology specialties joined together and the Center for Neuroscience Services and Research (P3Neuro). HUSM is one of the centers which performs DBS in Malaysia. The first DBS conducted here was in 2007. Up to present date, we have carried out 12 DBS surgeries in total.

Patients undergoing DBS require a multidisciplinary team approach to management. Patients were assessed pre-operatively in accordance with local guidelines to ascertain the severity of their respective diseases. Appropriate scoring systems which will be discussed were used to assess patients and these included the United Parkinson's Disease Rating Score, Unified Dystonia Rating Scale, Fahn Marsden Dystonia Scale, Yale Global Tic Scoring Scale and Connors ADHD Score. Experienced neurosurgeons, neuroanaesthesiologists and neurologists were involved in the DBS procedures. Postoperatively, these patients were followed up closely in clinics to monitor their progression using the same pre-operative scoring system.

\section{Patient characteristics}

Twelve of our patients underwent DBS. Their age range was between 22 and 67 years. Ten of them were males and two were females. Out of the 12 patients, seven had a diagnosis of Idiopathic Parkinson's Disease (IPD), three were diagnosed with dystonia and two with Tourette's Syndrome. The demographic data of these patients can be seen in Table 1. Patients diagnosed with IPD had an age range of 46 years to 67 years at surgery with a mean age of 56 years at surgery and 45 years at diagnosis. There

Table 1. Patient demographics and diagnosis (IPD $=$ idiopathic Parkinson's disease, $S T N=$ substantia nigra, $\mathrm{GPi}=$ globus pallidus internal)

\begin{tabular}{cccccc} 
Patient & Age & Sex & Diagnosis & Duration of illness (years) & DBS Target \\
1 & 54 & M & IPD & 11 & STN \\
2 & 46 & M & IPD & 6 & STN \\
3 & 53 & F & IPD & 10 & STN \\
4 & 60 & F & IPD & 10 & STN \\
5 & 54 & M & IPD & 14 & STN \\
6 & 67 & M & IPD & 10 & STN \\
7 & 61 & M & IPD & 15 & STN \\
8 & 60 & M & Dystonia & 3 & GPi \\
9 & 24 & M & Dystonia & 12 & GPi \\
10 & 29 & M & Dystonia & 26 & GPi \\
11 & 31 & M & Tourette's Syndrome & 14 & Medial thalamus \\
12 & 22 & M & Tourette's Syndrome & 16 & Medial thalamus \\
\hline
\end{tabular}


were three patients diagnosed with dystonia as detailed in Table 2. The characteristics of patients diagnosed with Tourette's syndrome are summarised in Table 3.

\section{Surgical outcomes}

Surgical outcomes for these patients were assessed based on their diagnosis. Patients with a diagnosis of IPD were assessed using the United Parkinson's Disease Rating Score (UPDRS), sections III and IV, which were scored both pre-operatively and post-operatively (as seen in Table 4 and Table 5). Pre-operatively, patients were assessed and scored both whilst on medications and off medications. Postoperatively, patients were scored whilst on medications at 3, 6, 12 and 24 months follow up. Both motor symptoms from the primary disease and secondary to medication side effects were evaluated.

Four out of seven patients had at least a $50 \%$ improvement at 3 months after surgery in their motor symptoms, and all 7 patients scored more than a 50\% improvement in their motor symptoms secondary to medical therapy

Table 2. Patients diagnosed with dystonia who underwent DBS

\begin{tabular}{|c|c|c|c|}
\hline & Case 1 & Case 2 & Case 3 \\
\hline Age at onset (years) & 57 & 12 & 3 \\
\hline Age at surgery (years) & 60 & 24 & 29 \\
\hline Type of dystonia & $\begin{array}{c}\text { Focal to generalised } \\
\text { dystonia }\end{array}$ & $\begin{array}{c}\text { Primary generalised } \\
\text { dystonia }\end{array}$ & $\begin{array}{c}\text { Primary generalised } \\
\text { dystonia }\end{array}$ \\
\hline Region affected by dystonia & $\begin{array}{l}\text { Cranio-cervical region } \\
\text { and extremities }\end{array}$ & Generalised & $\begin{array}{c}\text { Generalised predominantly } \\
\text { left extremity }\end{array}$ \\
\hline
\end{tabular}

Table 3. Patients diagnosed with Tourette's syndrome who underwent DBS

\begin{tabular}{lcc} 
& Case 1 & Case 2 \\
Age at onset (years) & 9 & 10 \\
Age at surgery (years) & 25 & 26 \\
Number of drug therapies prior to surgery & 4 & 6 \\
Major depression & Absent & Present \\
Obsessive compulsive disorder & Absent & Present \\
Attentional disorders & Present & Present \\
Others & Self-harming behavior, corprolalia & Absent \\
\hline
\end{tabular}

Table 4. UPDRS III scored pre-operatively and post-operatively

\begin{tabular}{|c|c|c|c|c|c|c|c|}
\hline \multirow{2}{*}{$\begin{array}{c}\text { United Parkinson's } \\
\text { Disease Rating } \\
\text { Score (UPDRS) III } \\
\text { Motor score }\end{array}$} & \multicolumn{2}{|c|}{ Before Surgery } & \multicolumn{4}{|c|}{ After surgery with medications } & \multirow{2}{*}{ Improvement } \\
\hline & $\begin{array}{c}\text { Off } \\
\text { medications }\end{array}$ & $\begin{array}{c}\text { On } \\
\text { medications }\end{array}$ & $\begin{array}{c}3 \\
\text { months }\end{array}$ & $\begin{array}{c}6 \\
\text { months }\end{array}$ & $\begin{array}{l}12 \\
\text { months }\end{array}$ & $\begin{array}{l}24 \\
\text { months }\end{array}$ & \\
\hline Case 1 & 35 & 7 & 3 & $\mathrm{O}$ & 2 & 3 & $57 \%$ at 3 months \\
\hline Case 2 & 40 & 21 & 11 & 12 & $\mathrm{n} / \mathrm{a}$ & $\mathrm{n} / \mathrm{a}$ & $48 \%$ at 3 months \\
\hline Case 3 & 30 & 18 & 13 & 13 & 12 & 12 & $83 \%$ at 3 months \\
\hline Case 4 & 50 & 6 & 2 & & Deceased & & $67 \%$ at 3 months \\
\hline Case 5 & 51 & 9 & 4 & 3 & 3 & 3 & $56 \%$ at 3 months \\
\hline Case 6 & 35 & 22 & 22 & 18 & 14 & 14 & $22 \%$ at 6 months \\
\hline Case 7 & 30 & 10 & 10 & 8 & 7 & $\mathrm{n} / \mathrm{a}$ & $20 \%$ at 6 months \\
\hline
\end{tabular}

n/a: not available 
Table 5. UPDRS IV scored pre-operatively and post-operatively

\begin{tabular}{|c|c|c|c|c|c|c|}
\hline \multirow{2}{*}{$\begin{array}{c}\text { United Parkinson's } \\
\text { Disease Rating Score } \\
\text { (UPDRS) IV } \\
\begin{array}{c}\text { Motor complication } \\
\text { score }\end{array}\end{array}$} & \multirow{2}{*}{$\begin{array}{l}\text { Before } \\
\text { surgery }\end{array}$} & \multicolumn{4}{|c|}{ After surgery } & \multirow{2}{*}{$\begin{array}{c}\text { Improvement } \\
\begin{array}{c}\text { (at } 3 \text { months } \\
\text { post-DBS) }\end{array}\end{array}$} \\
\hline & & $\begin{array}{c}3 \\
\text { months }\end{array}$ & $\begin{array}{c}6 \\
\text { months }\end{array}$ & $\begin{array}{c}12 \\
\text { months }\end{array}$ & $\stackrel{24}{\text { months }}$ & \\
\hline Case 1 & 13 & 2 & 2 & o & o & $85 \%$ \\
\hline Case 2 & 12 & 5 & 6 & $\mathrm{n} / \mathrm{a}$ & $\mathrm{n} / \mathrm{a}$ & $58 \%$ \\
\hline Case 3 & 9 & 2 & 2 & o & o & $78 \%$ \\
\hline Case 4 & 6 & $\mathrm{O}$ & Deceased & $100 \%$ & & \\
\hline Case 5 & 13 & 4 & 3 & 3 & 2 & $69 \%$ \\
\hline Case 6 & 6 & 2 & 3 & 2 & 2 & $67 \%$ \\
\hline Case 7 & 10 & 3 & 3 & 3 & $\mathrm{n} / \mathrm{a}$ & $70 \%$ \\
\hline
\end{tabular}

n/a: not available

at 3 months after surgery. Four out of seven patients did not experience further improvement in their motor symptoms at 6,12 and 24 months follow up after their initial improvement at 3 months. These patients also did not experience further improvement in their motor symptoms secondary to medical therapy.

The three patients diagnosed with dystonia were assessed using the Unified Dystonia Rating Scale (UDRS) and Fahn Marsden Dystonia Scale (FMDS). These patients were assessed pre-operatively and post-operatively at 3, 6, 12 and 24 months follow up. Results are shown in Table 6.

Two out of three patients diagnosed with dystonia reported improvement in their symptoms. Both patients experienced improvement in up to 6 months follow up after surgery, after which improvement plateaued. One patient with dystonia did not experience any improvement or worsening in symptoms in the first 6 months, though this patient subsequently reported some improvement at 12 months follow up, which then remained static at 24 months follow up.
Two of the patients with Tourette's Syndrome were objectively assessed using the Yale Global Tic Scoring Scale (as seen in Table 7) and Connors ADHD Score (as seen in Table 8).

\section{Surgical complications}

The complications encountered in our patients post-operatively are as listed in Table 9. We had one patient with Tourette's syndrome who developed a spontaneous intracranial haemorrhage shortly following DBS (8). Clinically, this patient complained of headaches with no new neurological deficit. The haemorrhage was found to have developed along the tract of the electrodes bilaterally. This patient did not require surgical intervention and was managed conservatively. Investigation later showed that this patient had low levels of factor XIIIA activity (8). Fenoy and Simpson studied 728 patients who underwent DBS and found symptomatic intracranial haemorrhage to occur in about $1.1 \%$ of their study sample; however, previous literature has reported risk of

Table 6. UDRS and FMDS scored in patients with dystonia pre-operatively and post-operatively

\begin{tabular}{|c|c|c|c|c|c|c|c|c|c|c|}
\hline \multirow{3}{*}{$\begin{array}{l}\text { Unified Dystonia } \\
\text { Rating Scale } \\
\text { (UDRS) \& Fahn } \\
\text { Marsden Dystonia } \\
\text { Scale (FMDS) }\end{array}$} & \multicolumn{2}{|c|}{ Before surgery } & \multicolumn{8}{|c|}{ After surgery } \\
\hline & \multirow[b]{2}{*}{ UDRS } & \multirow[b]{2}{*}{ FMDS } & \multicolumn{4}{|c|}{ UDRS } & \multicolumn{4}{|c|}{ FMDS } \\
\hline & & & $\begin{array}{c}3 \\
\text { months }\end{array}$ & $\begin{array}{c}6 \\
\text { months }\end{array}$ & $\begin{array}{c}12 \\
\text { months }\end{array}$ & $\begin{array}{c}24 \\
\text { months }\end{array}$ & $\begin{array}{c}3 \\
\text { months }\end{array}$ & $\begin{array}{c}6 \\
\text { months }\end{array}$ & $\begin{array}{c}12 \\
\text { months }\end{array}$ & $\begin{array}{c}24 \\
\text { months }\end{array}$ \\
\hline Case 1 & 88 & 78.5 & 10 & 8 & $4 \cdot 5$ & $4 \cdot 5$ & 5 & 3 & 3 & 3 \\
\hline Case 2 & 68.5 & $87 \cdot 5$ & 45 & 38 & 26 & 26 & 60 & 55 & 28 & 28 \\
\hline Case 3 & 26 & 71 & 26 & 26 & 22 & 22 & 71 & 71 & 65 & 65 \\
\hline
\end{tabular}


Brief Communication | Deep brain stimulation at HUSM

Table 7. Pre-operative and post-operative assessment using the Yale Global Tic Scoring Scale for patients with Tourette's Syndrome

\begin{tabular}{cccccc} 
Yale Global Tic & Before surgery & \multicolumn{4}{c}{ After surgery } \\
\cline { 3 - 6 } Scoring Scale & $\mathbf{3}$ months & $\mathbf{6}$ months & $\mathbf{1 2}$ months & $\mathbf{2 4}$ months \\
Case $\mathbf{1}$ & 100 & 64 & 60 & 60 & 55 \\
Case 2 & 94 & 60 & n/a & n/a & n/a \\
\hline
\end{tabular}

n/a: not available

Table 8. Pre-operative and post-operative assessment using Connors ADHD Score for patients with Tourette's Syndrome

\begin{tabular}{cccccc} 
Connors ADHD Score & Before surgery & \multicolumn{4}{c}{ After surgery } \\
\cline { 3 - 6 } & & $\mathbf{3}$ months & $\mathbf{6}$ months & $\mathbf{1 2}$ months & $\mathbf{2 4}$ months \\
Case 1 & 7 & 8 & 8 & 8 & 8 \\
Case 2 & 7 & n/a & n/a & n/a & n/a \\
\hline
\end{tabular}

n/a: not available

Table 9. Post-operative complications of DBS at HUSM from 2007 till 2015

\begin{tabular}{lc}
\multicolumn{1}{c}{ Complications } & Number \\
Procedure related & \\
- Symptomatic intracranial haemorrhage & 1 \\
- Seizures & 0 \\
- Infection & 0 \\
- Improper lead placement & 1 \\
Device related & \\
- Migration & 0 \\
- Infection & 2 \\
- Lead break & 1 \\
- Seroma & 1 \\
- Erosion & 1 \\
- Poor healing & 0 \\
- Intermittent dysfunction & 0 \\
Stimulation related & 1 \\
- Dyskinesia & \\
- Diplopia & 0 \\
- Dysarthria & 0 \\
- Headaches & 0 \\
- Paresthesia & 0 \\
\hline
\end{tabular}

infection to be between a range of $0 \%$ and $15 \%$ (9). The other patient with Tourette's Syndrome unfortunately developed an allergic reaction to the device. Due to this, the device had to be removed shortly after insertion.

One of the patients with IPD who developed a device-related infection was later found to have had frequent falls at home and lack of supervision from his caretaker. Due to this, the patient developed a haematoma over the
Implantable Pulse generator (IPG) placed in his anterior chest wall which later became infected and required removal. The next patient who developed device-related infection was a patient who had a background of IPD, diabetes mellitus type 2 and chronic eczema. This patient presented 3 months after DBS surgery with an erythematous scalp wound. His infection did not resolve despite a course of antibiotics and required wound exploration and revision of his 
IPG. He was then continued on another course of antibiotics. However, 3 months later, the patient returned to our attention again as he continued to have recurrent infections. He underwent a second wound re-exploration. Despite surgical management and prolonged antibiotics, the patient had a wound breakdown 18 months later. We proceeded then with removal of the implants, and the patient underwent unilateral radiofrequency ablation of the subthalmaic nucleus. The patient recovered well following this procedure. In Fenoy and Simpson's study, they found that the risk of infection was 3.1\% out of which $1.4 \%$ were self-limiting and $1.3 \%$ required surgical intervention (9).

Hariz suggested in his study that in order to prevent complications, patients should be selectively matched with specific DBS procedures according to their clinical, social and cognitive manifestations, and surgeries should be performed by an experienced and meticulous surgical team (10). Analysing most of our complications, clinical, social and cognitive circumstances of patients as per Hariz are aspects that we probably need to scrutinise in further detail when assessing their suitability for DBS.

\section{Conclusion}

DBS is still in its early years in Malaysia. Generally, we still lack large enough studies to assess the overall cost effectiveness and benefits of DBS in our community. However, literature published has clearly established the significantly positive outcomes of DBS patients which we assume theoretically will have similar outcomes in our community (11-14). We hope to be able to incorporate more neurological and psychiatric patients and establish more centres carrying out functional neurosurgery. Financial constraints are one of the main challenges we face that limit the wide use of DBS and are still yet to be overcome.

\section{Acknowledgement}

We would like to acknowledge Professor Sarun Nunta-Aree from the Department of Neurosurgery, Faculty of Medicine Siriraj Hospital, Mahidol University, Bangkok, Thailand and Ms Kavita Kaur from Medtronic, Thailand who has consistently supported us with training and technical support during the initiation of the Deep Brain Stimulation program in Hospital Universiti Sains Malaysia under the Department of Neurosciences, School of Medical Sciences, Universiti Sains Malaysia as well as the Center for Neuroscience Services and Research,Universiti Sains Malaysia. We are indebted to Professor Luc Calliauw, Professor Jacques Caemert, Professor Dirk Van Roost, Professor Dr Paul Boon from Gent, Belgium for the transfer of skills and knowledge to the visiting Malaysian team many years ago headed by Dato Dr Johari Adnan Siregar, Professor Dato Dr Jafri Malin Abdullah, Dr Dato Dr Hanip Rafia, and Dato Dr Mohd Saffari Mohd Haspani and Associate Professor Dato Dr Abdul Rahman Izaini Ghani.

\section{Authors' Contributions}

Conception and design: JMA, ARIG

Analysis and interpretation of the data: RK, TYC, DNF, LLH, SKR

Drafting of the article: DNF, LLH

Critical revision of the article for important intellectual content: JMA, ARIG

Final approval of the article: JMA, ARIG

Provision of study materials or patients: JMA, ZI,

ARIG, RK, JT, SAH, BI

Statistical expertise: DNF, LLH

Administrative, technical, or logistic support: DNF, BI Collection and assembly of data: ZI, JT, DNF, LLH, SKR

\section{Correspondence}

Associate Prof Dato Dr Abdul Rahman Izaini Ghani, MBBS (Queensland), Master Surgery (Neurosurgery) Universiti Sains Malaysia

Center for Neuroscience Services and Research USM \& Department of Neurosciences, Universiti Sains Malaysia, Jalan Hospital USM, 16150 Kubang Kerian, Kelantan, Malaysia Tel: +609 7676300

Fax: +609 7673833

E-mail: abrahmanghani@yahoo.com

\section{References}

1. Schwalb JM, Hamani C. The history and future of deep brain stimulation. Neurotherapeutics. 2008;5(1):3-13.

2. Wagner T, Valero-Cabre A, Pascual-Leone A. Noninvasive human brain stimulation. Annu Rev Biomed Eng. 2007;9:527-565. 
3. Higgins ES, George MS. Brain stimulation therapies for clinicians. 1st ed. Washington, DC; London: American Psychiatric Pub; 2009.

4. Higgins ES, George MS. The neuroscience of clinical psychiatry: the pathophysiology of behavior and mental illness. Philadelphia, London: Lippincott Williams \& Wilkins; 2007.

5. Sironi VA. Origin and evolution of deep brain stimulation. Front Integr Neurosci. 2011;5:42.

6. Kalinowsky LB. History of convulsive therapy. Ann N Y Acad Sci. 1986;462:1-4.

7. Delgado JM, Hamlin H, Chapman WP. Technique of intracranial electrode implacement for recording and stimulation and its possible therapeutic value in psychotic patients. Confin Neurol. 1952;12(5-6):315-319.

8. Idris Z, Ghani AR, Mar W, Bhaskar S, Wan Hassan WN, Tharakan $\mathrm{J}$, et al. Intracerebral haematomas after deep brain stimulation surgery in a patient with Tourette syndrome and low factor XIIIA activity. $J$ Clin Neurosci. 2010;17(10):1343-1344.

9. Fenoy AJ, Simpson RK. Risks of common complications in deep brain stimulation surgery: management and avoidance. $J$ Neurosurg. 2014;120(1):132-139.
10. Hariz MI. Complications of deep brain stimulation surgery. Mov Disord. 2002;17(Suppl 3):S162-S166.

11. Biolsi B, Cif L, Fertit HE, Robles SG, Coubes P. Long-term follow-up of Huntington disease treated by bilateral deep brain stimulation of the internal globus pallidus. $J$ Neurosurg. 2008;109(1):130-132.

12. Vingerhoets FJ, Villemure JG, Temperli P, Pollo C, Pralong E, Ghika J. Subthalamic DBS replaces levodopa in Parkinson's disease: two-year followup. Neurology. 2002;58(3):396-401.

13. Maciunas RJ, Maddux BN, Riley DE, Whitney CM, Schoenberg MR, Ogrocki PJ, et al. Prospective randomized double-blind trial of bilateral thalamic deep brain stimulation in adults with Tourette syndrome. $J$ Neurosurg. 2007;107(5):1004-1014.

14. Reza F, Begum T, Idris Z, Ghani ARI, Bhaskar S, Chin TY, Tharakan J, Abdullah JM. Root mean square (RMS) of neuronal discharge during functional neurosurgery. IEEE Proceeding. 2011:2192-2195. 